\title{
Equity-oriented Design in Open Education
}

\author{
Jeremiah H. Kalir \\ To appear in International Journal of Information and Learning Technology. \\ Correspondence concerning this manuscript should be addressed to: \\ Jeremiah H. Kalir \\ University of Colorado Denver \\ School of Education and Human Development \\ 1380 Lawrence Street, Suite 645 \\ Denver, CO 80204 \\ remi.kalir@ucdenver.edu I (303)315-0034
}

\section{Structured Abstract}

Purpose: The purpose of this article is threefold: a) to describe the equity-oriented design of a publicly accessible and openly networked computer-supported collaborative learning (CSCL) initiative that has supported educator discussion about equity topics; b) to identify design principles for equity-oriented design in open education; and c) to propose a model for the design of open learning initiatives that are mutually committed to educational equity and educational openness.

Design: This article draws from design-based research methodology, specifically design narrative and the worked example. The article is one response to the need for more "designerly work" in the learning sciences, generally, and more specifically in domains such as CSCL.

Findings: Four design principles are identified that informed the equity-oriented creation and iteration of the Marginal Syllabus, an open CSCL initiative: Leveraging the open web, fostering multi-stakeholder partnerships, working with open content, and engaging professional learning as an open practice. This article also advances the open palimpsests model for equity-oriented design in open education. The model integrates design principles to assist CSCL and open education designers and researchers in creating or iterating projects to be more equity-oriented learning opportunities.

Originality: This article's design narrative identifies Marginal Syllabus design principles and advances the open palimpsests model for equity-oriented design in open education. The design narrative demonstrates how critical perspectives on the relationship between equity and digital technology can encourage collaboration among diverse project stakeholders, attune to the dynamics of power and agency, and respond to the worldly needs of partners and participants.

\section{Keywords:}

annotation, CSCL, design research, equity-oriented design, open education 
Being honest about designing has the potential to aid us - and others - in acquiring insights for and about learning. By, in effect, holding back on what we suggest are authentic aspects of designing, we wonder if we are limiting the new and improved ideas that could benefit the future of education. - Svihla and Reeve (2016, p. 2)

\section{Introduction}

This article concerns equity-oriented design in open education. Among the questions about educational equity and openness guiding this study, I ask: How do equity-oriented designs privilege certain types of open technologies as mediating artifacts? How do these designs account for sociocultural practices and contexts when creating and describing openly accessible learning? And what of the political relevance of new social and technical configurations in creating more participatory and agentic learning? As will be discussed, I draw upon the concept of infrastructuring (Björgvinsson et al., 2012) to share a design narrative about an open education project that has been shaped over time, by multiple stakeholders, and is of relevance to everyday learning practices. In response to the guiding interest of this special issue - how equity is taken up in discourse and practice across learning settings that feature digital technologies - I detail a design for infrastructuring learning that is simultaneously committed to greater educational equity and educational openness.

It is necessary, at the outset, to frame how I approach terms like equity, equity-oriented, and equitable, particularly as these terms relate to infrastructuring open education with digital technology. First, and as regards equity, I agree with Attewell's (2001) concern for both access to and use of digital technology, and further appreciate how Warschauer and Matuchniak (2010) extend this framing of equity to also include outcomes. Second, I adopt Teeters and colleagues' (2016) approach to equity-oriented design and research in the learning sciences: "Our methodologies aim to... address the situated and distributed nature of learning. We take up this challenge while foregrounding equity. We recognize that if we seek to generate equitable outcomes, the processes by which we enact change must be orchestrated such that equity is embedded in every stage" (p. 52). And third, my stance toward equity and digital technology echoes Selwyn and Facer's (2013) critique of "technicist" conceptions of educational technology that view tools as a panacea promising immediate and effective intervention. Alternatively, Selwyn and Facer suggest a political perspective that draws upon critical traditions of educational inquiry to foreground concern with power, control, and agency. Specifically:

The use of digital technology in educational settings is often not a wholly inclusive, dialogic, or equitable process in which all actors have equal power in participating, and where all actors can determine what educational technology is or how it is used. The critical take on educational technology is therefore often 
driven by a desire to redress the imbalances of power that reside within most educational uses of technology. (p. 14)

Collectively, access to, participation in, and outcomes associated with equity-oriented design aim to create more inclusive, dialogic, and fair learning processes as supported by digital technology. And more equitable learning design can thereby create - as the intended outcome of such design processes - participatory pathways for stakeholders to shape what counts as learning technology, and how such technology is used to redress imbalances of power, expression, and agency.

\section{Theoretical Perspective}

This study's theoretical perspective draws from Björgvinsson and colleagues' (2012) approach to design. Reporting upon an initiative attuned to the complexities of equity-oriented design is a means, from this perspective, toward "envisioning emerging landscapes of design through which social and material transformations take place, landscapes shaped by the opening up of questions and possibilities" (p. 109). For Björgvinsson and colleagues, such “opening up" occurs through infrastructuring, or a relational approach to socio-material design that spans time, engages both professional designers and participants as co-designers, is ongoing, and embraces the unexpected and emergent. While infrastructuring creates, as one outcome, a particular type of designed artifact (a "Thing"), such processes of entanglement also modify interactional space - yet not in a universal sense, but in a way that is always partial, marginal, and political. Accordingly, infrastructuring is an appropriate perspective through which to perceive equity-oriented design in "political communities [that] are characterized by heterogeneity and difference" (p. 116).

The utility of infrastructuring as a design perspective is apparent when surveying one domain of the learning sciences expressly concerned with the role of technology in mediating group collaboration, shared knowledge construction, and the negotiation of meaning. Trends in computer-supported collaborative learning (CSCL) are increasingly attentive to the ways in which learning technologies can, under certain circumstances, be co-designed to mediate more accessible and equitable learning (Smith et al., 2017). An equity-oriented reading of the CSCL literature reveals persistent concerns about who does (and does not) have access to high-quality learning designs (such as girls and young women; see Hsi and Hoadley, 1997; Simpson et al., 2017), how educators participate in design activities (i.e. Kali et al., 2015), and what counts as consequential design and learning for non-dominant youth (i.e. Pinkard et al., 2017). As Stahl and colleagues (2006) suggest, "The goal for design in CSCL is to create artifacts, activities, and environments that enhance the practices of group meaning making" (p. 488). However, the extent to which enhanced group practices for shared meaning making do indeed engender more equitable learning is ambiguous; that is, this definition of CSCL design does not explicitly address equity, power, and the political. Nonetheless, strands of CSCL research indicate a continued need for equity-oriented approaches to the design of such collaborative meaning 
making so as to broaden accessible learning opportunities, enhance participation structures, and work toward greater learner agency (Wise and Schwarz, 2017).

Infrastructuring is also a useful means of "opening up new ways of thinking and behaving" (Björgvinsson et al., 2012, p. 102) in relation to the equity-oriented design of open education. The proliferation of open educational resources (OER), as one facet of open education, have foregrounded equity-adjacent concerns by emphasizing a range of accessible licensing permissions, such as the ability for anyone to reuse, remix, and redistribute educational content (Green, 2017). More recently, research and commentary has suggested these resources can play an important role in cultivating more equitable learning opportunities by reducing student textbook costs, lowering barriers to college affordability, and catalyzing more socially just forms of education (i.e. Biswas-Diener and Jhangiani, 2017; DeRosa, 2017). Related developments in open educational practices (OEP) have also helped to position deliberations about open education in relation to "power relations and inequality" (Cronin, 2017, p. 16), as well as recognition that "openness in education is not a movement for the emancipation of resources, but of people and practice" (Havemann, 2016, p. 7). Yet despite these encouraging developments in the design of both OER and OEP, Reich and Ito (2017) observe that open is not equivalent to equitable: "As intuitive as the idea sounds, however, free and open technologies do not democratize education. In fact, evidence is mounting that free online learning materials disproportionately benefit the affluent and highly educated" (original emphasis; p. 7). A need persists to better articulate and demonstrate the conditions under which open educational initiatives, resources, and practices meaningfully contribute to equity-oriented learning designs and opportunities.

\section{Methodology}

Having presented a theoretical perspective on design, sketched a scholarly context, and noted a set of motivating research needs, I now accept Svihla and Reeve's (2016) suggestion for more "designerly work" in the learning sciences. For the past two years, I have helped shepherd a design-based research (DBR) effort investigating educator participation in an open CSCL environment. Here, I draw upon methodological traditions within DBR of design narrative (Bell et al., 2004) and the "worked example" (Barab et al., 2009) to describe the equity-oriented design of an open CSCL environment that has supported educator collaborative discourse about equity topics. My narrative methods attend to design context and detail how tools and activities changed over time. I also highlight principles, data, and processes relevant to both design theory and project stakeholders as co-designers. While this initiative - the Marginal Syllabus - has successfully encouraged educator discussion about equity topics, an important distinction is necessary; this article concerns the centrality of equity-oriented design methods (Teeters et al., 2016) when infrastructuring the Marginal Syllabus, in contrast to reporting inquiry about how educators discuss equity topics as an indicator of their interest-driven professional learning (i.e. 
Kalir and Perez, in press). The purpose of this design narrative is to systematically recount and critically consider how mutually supportive commitments to educational equity and openness propelled this effort forward.

In narrating the infrastructuring of the Marginal Syllabus, I echo Svihla and Reeve's (2016) emphasis on design as a multidisciplinary practice responsive to "worldly needs." In this case, worldy needs are associated with educators, including those teaching in K-12 and postsecondary settings, and whose professional learning is too frequently dictated by administrative concern rather than self-directed by authentic care for student wellbeing or social responsibility (Kalir, 2018). Moreover, while design may be a "first-class research activity," there is a methodological need to better document iterative and emergent design processes and outcomes (Kolodner et al., 2016). In response, I first describe the Marginal Syllabus' design context, including four guiding design principles informed by the relationship between educational equity and educational openness. I then present a model that emerged as a result of these design principles and that has helped infrastructure the Marginal Syllabus toward its third iteration. After discussing two key design decisions that helped iterate the Marginal Syllabus, I conclude with a discussion about implications for equity-oriented design research in both CSCL and open education.

\section{Design Context and Principles}

In the summer of 2016, I began collaborating with members of a fledgling design team including a K-12 educator and a representative from a technology organization - to explore how developments in open education might support educators' interest-driven learning about equity. These conversations were grounded in real-world concerns pertinent to the professional lives of educators. Despite dominant media narratives about apathetic educators disinterested in professional growth, we knew of many educators who wanted to read challenging texts, ask themselves and their peers tough questions, and engage in robust deliberation - particularly about issues that mattered. Furthermore, and despite dominant professional narratives about educators'

diminished capacity to commit limited resources (i.e. time, energy) to interest-driven learning, we had each collaborated with networks of educators who valued opportunities for collaboration across digital spaces. These initial conversations - which have now persisted in various forms and amongst an expanded design team for over two years - prompted infrastructuring of the Marginal Syllabus.

The Marginal Syllabus is a public CSCL initiative that convenes and sustains online conversations with educators about equity in education via open web annotation (OWA). The project's name is an intentional reference to multiple interpretations of the term marginal. First, the initiative collaborates with authors whose writing may be considered contrary to dominant education norms. The Marginal Syllabus is like an online book club, though the texts read and annotated are equity-oriented counternarratives to the educational status quo. Second, the 
Marginal Syllabus hosts and curates publicly accessible conversations among educators that occur in the margins of online texts via OWA. By opening up and digitizing how marginalia is jotted inside a book, OWA provides a publicly accessible and collaborative annotation layer whereby group social interaction includes reading and writing the web through multimodal commentary (Kalir and Dean, 2018). Third, the Marginal Syllabus mediates educator collaboration using a technology that was neither developed nor initially intended for use in a learning context. In contrast to commercial educational technology and social media, both of which are used for educator learning yet reify corporate influence of education, the Marginal Syllabus embraced Hypothesis, an open-source web annotation technology developed by the eponymous non-profit organization. How, though, did our design team infrastructure an open approach to educator learning? Over time, we have identified four design principles that have centered equity commitments when creating and facilitating this open CSCL initiative.

\section{Leverage the Open Web}

Educators can leverage the open web, including the use of open-source software, as a means of advancing their professional learning. Much (commercial) educational technology remains siloed - online yet closed, digital yet disconnected - from the shareable and linked features of the web. The social and technical development of the open web has advocated principles of accessibility, decentralization, and transparency (Berners-Lee, 2010). While there has been limited use of open-source technology within CSCL (exceptions include Calvani et al., 2006), our design team was committed to using open web tools, like Hypothesis, that exemplify both the technical standards of interoperability and the social norms of distributed knowledge production (Kalir and Dean, 2018). We leveraged Hypothesis, and the open web generally, as a first step toward orienting educators toward more equitable engagement with digital tools, spaces, and relations.

\section{Foster Multi-stakeholder Partnerships}

Our design team formed through intentional partnering that has connected K-12 educators, university researchers, Hypothesis, and the National Writing Project. Our attention to the opportunities and challenges of partnering has led to a secondary set of relationships with authors, the publishers of academic literature, and like-minded K-12 educators and universitybased teacher educators. Partnerships among diverse stakeholders are a well-documented and distinguishing feature of DBR (i.e. Collins et al., 2004). As our work has matured over time, the growth of our design team, project scope, and participant community has come to reflect a broader commitment to fostering educator professional learning through networked and collaborative partnerships. An equity-oriented approach to multi-stakeholder partnerships has required that we honor conflict, practice flexibility, and privilege adaptability and perspectivetaking as we work with tools and one another. 


\section{Work with Open Content}

Our engagement with project stakeholders has helped us craft different strategies for working with various types of open content. First, we obtain consent from authors to publicly annotate their writing using Hypothesis. This requires that we find (sometimes creative) means of sharing their work as open access (OA) scholarship. Second, we guide educators in recognizing that their public participation via OWA produces open content. Our use of Hypothesis OWA attributes via Creative Commons licensing a public domain dedication to all participants' public annotation. In other words, the layer of annotation conversation produced by educators is an OER; it can be reused, remixed, and redistributed by others. Third, university researchers have access to this open data as another type of OER - learning analytics (i.e. Atenas and Havemann, 2015). Designing an equity-oriented and open CSCL initiative has meant provisioning multiple project stakeholders with the know-how and support to both contribute and work with open content.

\section{Engage Professional Learning as an Open Practice}

Educator professional learning can be approached as an open practice framed by commitments to transparency, reflection, and critical inquiry. While initial definitions of OEP hewed closely to supporting educator use and (re)production of OER (i.e. Ehlers, 2011), more recent articulation of what counts as OEP has grown to include open pedagogy, critical use of digital media, and educator co-design of publicly accessible and extensible learning architectures (Cronin, 2017; DeRosa and Jhangiani, 2017). Our stance toward professional learning as an open practice embraces Havemann's (2016) "ethos” of transparent academic activities "such as blogging, tweeting, presenting, and debating scholarly and pedagogic activities, in ways that promote reflection, reusability, revision, and collaboration" (p. 6). OWA can be a transparent academic activity that raises questions, reveals biases, builds solidarity, and sparks professionally-relevant connections. Educators who voluntary participate in the Marginal Syllabus' public annotation conversations have chosen to practice new forms of interest-driven professional learning across openly-networked online spaces.

\section{An Open Palimpsest Model}

Our design team has infrastructured the Marginal Syllabus as an open CSCL initiative by leveraging the open web, fostering multi-stakeholder partnerships, working with open content, and engaging professional learning as an open practice. This equity-oriented outcome was possible only because we frequently enacted these design principles in tandem. For example, guiding educator participation in OEP has helped us better introduce and scaffold the use of open-source technology; and vice versa, as the affordances of the open web clarify how we have articulate the breadth and possibility of open practices. Inspired by the social practices of annotation which afford novel perspective on both an original source text and emergent 
intertextuality (Brown and Duguid, 1996), I now present a second and complementary outcome the four previously discussed design principles in unison as an open palimpsest model for equityoriented design in open education (Figure 1).

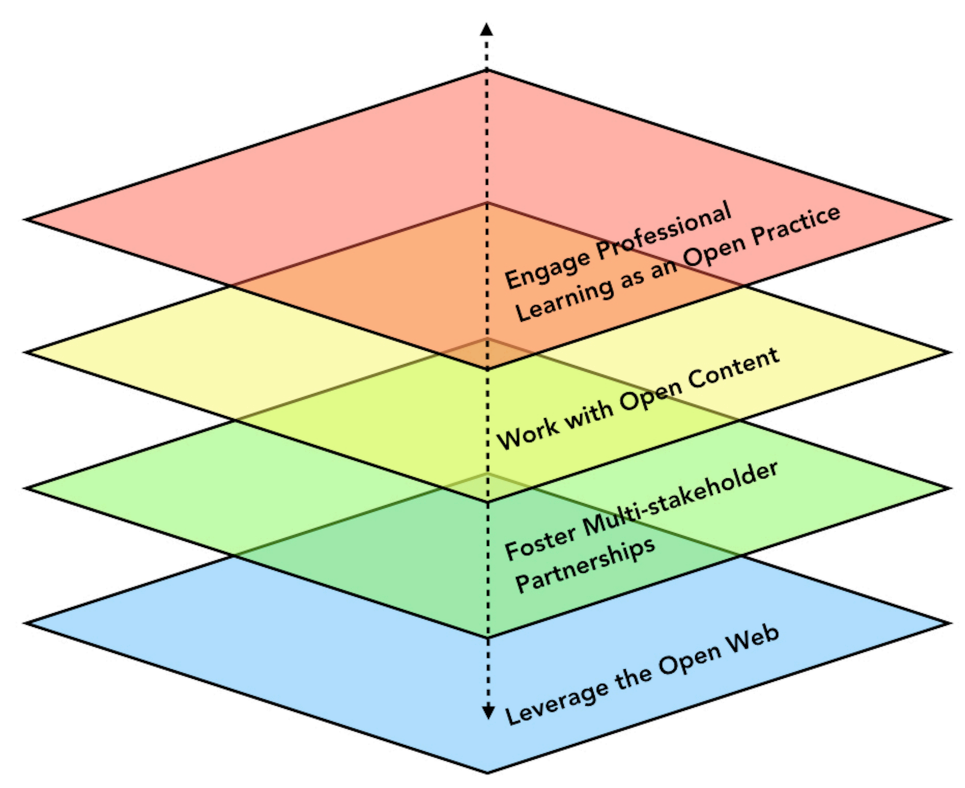

Figure 1. Open palimpsest model for equity-oriented design in open education

A palimpsest is a writing material, like a piece of paper or a tablet, that has been used one or more times and displays a diversity of layers, or strata featuring varied inscriptions, collectively apparent beneath the surface. Whether with palimpsests like the Books of Kells or a wall tagged repeatedly with graffiti, these multi-authored texts reveal upon careful examination the importance of any individual layer as well as the distinctiveness of the integrated whole. Similarly, the open palimpsest model suggests that individual design principles may be layered together in complementary fashion, thereby "opening up new ways of thinking and behaving" (Björgvinsson et al., 2012, p. 102) when designing more equitable and open learning. As an outcome of equity-oriented infrastructuring, Figure 1 represents how a particular set of design principles may be actualized to embrace commitments to both educational equity and educational openness during processes of design.

\section{Infrastructuring and Iterating the Marginal Syllabus}

The open palimpsest model for equity-oriented design in open education emerged from the principle-driven infrastructuring of the Marginal Syllabus. With the model as a reference, my design narrative now presents two key developments in this open CSCL initiative. Rather than present a linear review of the Marginal Syllabus from 2016-17 through 2017-18, I share notable design decisions that helped iterate the project and better orient our design team's integrated commitments to educational equity and openness. 


\section{From Flash Mobs to Sustained Conversations}

When the Marginal Syllabus started, in August of 2016, educators were invited to join open and collaborative annotation as an activity akin to a flash mob. This descriptor was chosen because both OWA and flash mobs are social endeavors and, frankly, we thought that promoting "annotation flash mobs" would be attractive to participants. While the idea of a flash mob did effectively convey excitement and spontaneity, the comparison quickly became insufficient as both a public-facing analogy and as an organizing strategy. What motivated our decision to change the way we organized, facilitated, and promoted the Marginal Syllabus?

First, flash mobs are quick bursts of activity. While we initially scheduled and facilitated the Marginal Syllabus for about an hour once a month (i.e. "Starting at $6 \mathrm{p}$ gather at this online document for an annotation flash mob"), educator dialogue often lasted for days if not weeks, suggesting social reading could be quite slow and thoughtful rather than quick and superficial. Second, while flash mobs are sophisticated orchestrations of shared activity, they are also often an effort of collective uniformity (i.e. many people doing precisely the same thing at exactly the same time). While it was accurate to describe Marginal Syllabus participants as collectively engaging in the social and collaborative practices of OWA, individually authored content was divergent in topic and tone, uniquely expressive and multimodal, and evidence of what Prior (2001) has described as the "multi-voiced" qualities of multiple authors who "intermingle" in a text. Third, flash mobs are distinctive because they mobilize playful improvisation among mundane routines of the everyday. Yet the traces of such dissonant creativity are often fleeting; an observer might never know that a flash mob had sprung to life in that location just over there about an hour ago. Alternatively, OWA affords multiple means of searchable curation and descriptive tagging, creating an indelible and shareable digital record that can be referenced as an archive of collaborative discourse (even when such OWA is playful and improvisational). Starting in March of 2017, our design team shifted away from flash mobs as both structure and analogy; instead, we began to organize sustained and week-long conversations. Ever since, Marginal Syllabus conversations have been scheduled for the first full week of a given month, with continued conversation encouraged throughout the remainder of the month.

How did our shift from flash mobs to sustained conversations reflect the equity-oriented design principles of the open palimpsest model? This decision was made primarily in response to public and private feedback from K-12 and international educators who observed that an hour-long flash mob was not accessible; the Marginal Syllabus, from their perspective, was restricted by duration and time zone. Shifting to a sustained conversation format: a) provided more time for first-time participants to adopt and familiarize themselves with Hypothesis OWA; b) honored the needs and interests of diverse stakeholders; c) created a more accessible structure so that 
participants could substantively work with open content over time; and d) aligned more favorably with the robust dialogic activities that characterize OEP.

\section{From a Piecemeal to a Curated Syllabus}

The Marginal Syllabus was launched and initially organized in piecemeal fashion. Unlike a more conventional syllabus associated with an academic course, and which clearly delineates a scope of readings planned for a semester or year, the Marginal Syllabus cobbled together month-tomonth author partnerships and scrambled to secure, host, and archive OA versions of their texts. After six months, it became abundantly clear that this strategy was unstainable over the longterm and stressful for our fledgling design team. Moreover, this approach to the orchestration and curation of public annotation conversation was creating a syllabus characterized by topical inconsistency rather than coherence. If the 2016-17 Marginal Syllabus was a course, what was the thematic objective? While each text and OWA conversation addressed important issues of educational equity - such as critical literacy instruction and culturally relevant pedagogy breadth of interest across topics diminished sustained and collective inquiry about shared questions and specific concerns.

About this time, the Marginal Syllabus design team began a series of conversations with leadership from the National Writing Project's Educator Innovator initiative. These exploratory discussions addressed how we might collaboratively and more sustainably support educators as they pursued openly networked and interest-driven professional learning. Educator Innovator had a distinctive history organizing and facilitating educator learning at the intersection of open education, new media literacy, and digital technology (i.e. Garcia, 2014). Moreover, Educator Innovator leaders were familiar with Hypothesis and excited about the potential of collaborative OWA to support educator learning. After piloting two collaboratively organized and sustained annotation conversations during April and May of 2017, we expanded our design team through a formal partnership. As a result, the 2017-18 Marginal Syllabus was hosted by the National Writing Project and was organized around the theme "Writing Our Civic Futures." Starting in September of 2017, educators were invited to join eight curated conversations featuring 12 partner authors. The purpose of the syllabus, as a whole, was to assist educators in discussing civic imagination and education, exploring their own connected learning and teaching, and collaboratively writing shared civic futures.

How did the creation of a curated and thematic - rather than piecemeal and opportune - syllabus reflect the equity-oriented design principles of the open palimpsest model? Designing the Marginal Syllabus' second iteration as a thematically coherent syllabus: a) demonstrated how open web values (i.e. accessibility, transparency) aligned with the content of a new educator professional learning design; b) galvanized and drew upon the strengths of an expanded partner network and design team; c) modeled how to curate topical, accessible, and annotatable open 
content; and d) illustrated how educators' openly networked and interest-driven professional learning could be situated via OWA across multiple sociopolitical texts and contexts.

\section{Discussion}

This design narrative asserts there is a need for equity-oriented design in both the learning sciences (and, in particular, domains like CSCL) as well as in open education. A critical perspective on the relationship between equity and digital technology can usefully delineate how equity-oriented design methods encourage collaboration among stakeholders, attune to the dynamics of power and agency, and respond to the worldly needs of partners and participants (like educators). In an attempt to help shape scholarly discourse and design, I have drawn upon the design theory of infrastructuring to advance a model pertinent to learning initiatives with dual commitments to educational equity and educational openness. The open palimpsests model for equity-oriented design in open education suggests that design principles may be layered together - in strategic and complementary fashion - so that the relevance of any given principle informs design decisions while, simultaneously, all the principles influence more equitable outcomes.

With limited focus on open technologies and environments in CSCL, the equity-oriented design methods discussed in this article suggest tangible opportunities for CSCL research. As noted, more conventional design goals in CSCL (i.e. Stahl et al., 2006) might be productively extended to position digital technology as supportive of collaborative meaning making while also responding to - or at least acknowledging - attendant equity topics and concerns. In this case, initiatives like the Marginal Syllabus demonstrate equity-oriented commitments at multiple levels of CSCL design: as central to the content of educators' professionally-relevant meaning making; as evident in the open tools and processes that shape activity structures and participation patterns; and as practiced amongst a design team's recognized challenges and opportunities during iterative decision-making. Moreover, the critical approach to educational technology advocated by Selwyn and Facer (2013) serves as a reminder that the design of any (digital) learning tool, process, or environment cannot be cleanly demarcated from the realities of sociopolitical context. For CSCL researchers and designers with resonant epistemological and methodological commitments, perhaps the open palimpsests model provides guidance for creating or iterating projects as more equity-oriented endeavors. Future CSCL research should apply, adapt, and also critique the open palimpsests model so that it, too, becomes a more responsive design scaffold for context-specific learning opportunities.

The open palimpsests model for equity-oriented design is also an attempt to recognize, and redress, Reich and Ito's (2017) observation of the false equivalence between educational openness and educational equity. Yes, the use of OER is important. Nonetheless, the open palimpsests model emphasizes a principle like equitable partnering so that designers might

mitigate "creative redlining" (Jhangiani, 2018) associated with who does (and does not) create 
OER, who is (and is not) compensated for such labor, and who accesses (and who remains unaware of) such resources. Similarly, OER integration among learning environments (including the commercial LMS) is necessary. The open palimpsests model, however, suggests commitments to the open web and OEP might help designers recognize that many learning infrastructures remain willfully ignorant of - or apathetic to - expansive visions of educational equity that far surpass the mere use of freely available educational content. One motivation to articulate the Marginal Syllabus' design principles, and to then propose a model for equityoriented design in open education, is precisely because advances in the development, use, and study of OER and OEP can approach equity as a task to be fulfilled rather than as a value to be continuously and creatively enacted. In this respect, a comment by Marginal Syllabus partner author Nicole Mirra (2017), written following her participation in collaborative OWA, indicates that activity designed according to the open palimpsests model can foster equity-oriented outcomes: "This practice can help chip away at the barriers that divide universities and communities and turn scholarly monologues into democratic dialogues" (par. 8). Like the Marginal Syllabus, the open palimpsests model is intended to provoke more democratic dialogue about equity-oriented design in open education.

Equity-oriented design should be considered whenever scholars, designers, and educators pursue a project that takes seriously commitments to both educational equity and educational openness. If a design team intends to create digital technology that surpasses concern for access and use, then robust design methods are needed to infrastructure new questions and possibilities as equity-oriented outcomes. This article has suggested one such approach that has guided the iterative development of the Marginal Syllabus as an open CSCL initiative. Integrated design principles, such as those which define the open palimpsests model, can help orient technologysupported learning initiatives toward more open and equitable activity by affording multiple entry points for project partners and divergent pathways for those who participate. In ideal circumstances, outcomes of equity-oriented design in open education redress who has the power to inform decision-making and shared activity, what forms of learner agency contribute to and produce new knowledge, and how digital technologies are transparently leveraged to support transformative learning. 


\section{References}

Atenas, J. and Havemann, L. (Eds.), (2015), Open Data as Open Educational Resources: Case Studies of Emerging Practice, Open Knowledge Open Education Working Group, London, UK.

Attewell, P. (2001), “Comment: The first and second digital divides," Sociology of Education, Vol. 74 No. 3, pp. 252-259.

Barab, S., Dodge, T. and Gee, J.P. (2009), "The worked example: Invitational scholarship in service of an emerging field," paper presented at the Annual Meeting of the American Education Research Association (AERA), San Diego, California.

Bell, P., Hoadley, C.M. and Linn, M.C. (2004), "Design-based research in education,” Linn, M., Davis, E., and Bell, P. (Eds.), Internet Environments for Science Education, Lawrence Erlbaum Associates, Mahwah, New Jersey, pp. 73-85.

Berners-Lee, T. (2010), "Long live the web," Scientific American, Vol. 303 No. 6, pp. 80-85. Biswas-Diener, R. and Jhangiani, R. S. (2017), "Introduction to open," Jhangiani, R. S. and Biswas-Diener, R. (Eds.), Open: The Philosophy and Practices that are Revolutionizing Education and Science, Ubiquity Press, London, UK, pp. 3-7.

Bjögvinsson, E., Ehn, P. and Hillgren, P.A. (2012), "Design things and design thinking: Contemporary participatory design challenges,” Design Issues, Vol. 28 No. 3, pp. 101116.

Brown, J.S. and Duguid, P. (1996), “The social life of documents," First Monday, Vol. 1 No. 1, available at: http://firstmonday.org/ojs/index.php/fm/article/view/466/387 (accessed 03 June 2018).

Calvani, A., Fini, A., Pettenati, M., Sarti, L. and Masseti, M. (2006), "Design of collaborative learning environments: Bridging the gap between CSCL theories and open source platforms," Journal of E-learning and Knowledge Society, Vol. 2 No. 1, pp. 61-74.

Collins, A., Joseph, D. and Bielaczyc, K. (2004), "Design research: Theoretical and methodological issues," The Journal of the Learning Sciences, Vol. 13 No. 1, pp. 15-42.

Cronin, C. (2017), “Open education, open questions," Educause Review, Vol. 52 No. 6, available at: https://er.educause.edu/articles/2017/10/open-education-open-questions (accessed 03 June 2018).

DeRosa, R. (2017), “OER: Bigger than affordability,” available at: https://www.insidehighered.com/digital-learning/views/2017/11/01/oer-catalyst-nationalconversation-about-public-higher-education (accessed 03 June 2018).

DeRosa, R. and Jhangiani, R. (2017), “Open pedagogy,” Mays, E. (Ed.), A Guide to Making Open Textbooks with Students, Rebus Community, Montreal, QC, pp. 6-21.

Ehlers, U.D. (2011), "Extending the territory: From open educational resources to open educational practices," Journal of Open Flexible and Distance Learning, Vol. 15 No. 2, pp. 1-10.

Garcia, A. (Ed.), (2014), Teaching in the Connected Learning Classroom, Digital Media and 
Learning Research Hub, Irvine, CA.

Green, C. (2017), “Open licensing and open education licensing policy," Jhangiani, R. S. and Biswas-Diener, R. (Eds.), Open: The Philosophy and Practices that are Revolutionizing Education and Science, Ubiquity Press, London, UK, pp. 29-41.

Havemann, L. (2016), “Open educational resources,” Peters, M. A. (Ed.), Encyclopedia of Educational Philosophy and Theory, Springer Singapore, Singapore.

Hsi, S. and Hoadley, C.M. (1997), "Productive discussion in science: Gender equity through electronic discourse," Journal of Science Education and Technology, Vol. 6 No. 1, pp. 23-36.

Jhangiani, R. (2018), “OER, equity, and implicit creative redlining,” available at: https://thatpsychprof .com/oer-equity-and-implicit-creative-redlining/ (accessed 03 June 2018).

Kali, Y., McKenney, S. and Sagy, O. (2015), “Teachers as designers of technology enhanced learning," Instructional Science, Vol. 43 No. 2, pp. 173-179.

Kalir, J. (2018), “Bit, block, sketch, build: Bricolage and educator learning," Hybrid Pedagogy, available at: http://hybridpedagogy.org/bit-block-sketch-build-bricolage/ (accessed 03 June 2018).

Kalir, J. and Dean, J. (2018), "Web annotation as conversation and interruption," Journal of Media Practice, Vol. 19 No. 1, pp. 18-29.

Kalir, J. and Perez, F. (in press), "The Marginal Syllabus: Educator learning and web annotation across sociopolitical texts and contexts," Reid, A. (Ed.), Marginalia in Modern Learning Contexts, IGI Global, Hershey, PA.

Kolodner, J., Christensen, B., Reeve, R., and Svihla, V. (2016), "Reflections on design stories," Svihla, V. and Reeve, R. (Eds.), Design as scholarship: Case studies from the learning sciences, Routledge, New York, NY: pp. 130-149.

Mirra, N. (2017), "Fostering democratic dialogue with digital annotation," available at: https://dmlcentral.net/fostering-democratic-dialogue-digital-annotation/ (accessed 03 June 2018).

Pinkard, N., Erete, S., Martin, C.K. and McKinney de Royston, M. (2017), "Digital Youth Divas: Exploring narrative-driven curriculum to spark middle school girls' interest in computational activities," Journal of the Learning Sciences, Vol. 26 No. 3, pp. 477-516.

Prior, P. (2001), "Voices in text, mind, and society: Sociohistoric accounts of discourse acquisition and use," Journal of Second Language Writing Vol. 10 No. 1, pp. 55-81.

Reich, J. and Ito, M. (2017), From Good Intentions to Real Outcomes: Equity by Design in Learning Technologies, Digital Media and Learning Research Hub, Irvine, CA.

Selwyn, N. and Facer, K. (2013), "Introduction: The need for a politics of education and technology," Selwyn, N. and Facer, K. (Eds.), The Politics of Education and Technology: Conflicts, Controversies, and Connections, Palgrave Macmillan, New York, NY, pp. 117.

Simpson, A., Bannister, N. and Matthews, G. (2017), “Cracking her codes: Understanding shared 
technology resources as positioning artifacts for power and status in CSCL

environments," International Journal of Computer-Supported Collaborative Learning, Vol. 12 No. 3, pp.221-249.

Smith, B., Borge, M., Mercier, E., and Lim, K. (Eds.), (2017), Making a Difference: Prioritizing Equity and Access in CSCL 12th International Conference on Computer Supported Collaborative Learning in Philadelphia, PA, 18-22 June, 2017, International Society of the Learning Sciences.

Stahl, G., Koschmann, T., and Suthers, D. (2006), "Computer-supported collaborative learning," Sawyer, K. (Ed.), The Cambridge Handbook of The Learning Sciences (2nd Ed.), Cambridge University Press, New York, NY, pp. 479-500.

Svihla, V. and Reeve, R. (2016), "Untold stories," Svihla, V. and Reeve, R. (Eds.), Design as Scholarship: Case Studies from the Learning Sciences, Routledge, New York, NY, pp. 110 .

Teeters, L., Jurow, A. S., and Shea, M. (2016), "The challenge and promise of community codesign," Svihla, V. and Reeve, R. (Eds.), Design as Scholarship: Case Studies from the Learning Sciences, Routledge, New York, NY, pp. 41-54.

Warschauer, M., and Matuchniak, T. (2010), "New technology and digital worlds: Analyzing evidence of equity in access, use, and outcomes," Review of Research in Education, Vol. 34 No. 1, pp. 179-225.

Wise, A.F. and Schwarz, B.B. (2017), "Visions of CSCL: Eight provocations for the future of the field," International Journal of Computer-Supported Collaborative Learning, Vol. 12 No. 4, pp. 423-467. 